\title{
Comparative analyses of different modelling approaches to simulate radionuclide transport through the Dnieper reservoirs based on extremal flood 1999 scenario
}

\author{
O.V. Voitsekhovich, M. Zheleznyak ${ }^{1}$ and L. Monte ${ }^{2}$ \\ Ukrainian Hydrometeorological Institute, Nauka Av. 37, $251028 \mathrm{Kiev}$, Ukraine \\ ${ }^{1}$ Institute of Mathematical Machines and Systems, National Academy of Ukraine, \\ Prospect Glushkova 42, 03187 Kiev, Ukraine \\ ${ }^{2}$ ENEA, Italy
}

\begin{abstract}
The highest flood since the Chernobyl accident took place in River Pripyat in spring 1999. The most contaminated left-side flood-plain upstream the Chernobyl Nuclear Plant has been protected from flooding by a dike constructed in 1992. However right-side flood plain was inundated within a month. Near the Yanov Bay the shallow waste storage sites were inundated. The concentration of ${ }^{90} \mathrm{Sr}$ in the water discharged from this territory to the river has increased to $100000 \mathrm{~Bq} / \mathrm{m}^{3}$ at the end of the flooding. The maximum concentration of ${ }^{90} \mathrm{Sr}$ in the river Pripyat the city of Chernobyl was $2000 \mathrm{~Bq} / \mathrm{m}^{3}$. The propagation of the sharp pick of radionuclide concentration was monitored in Dnieper reservoir cascade for, approximately, six months. The measured data were processed by statistical methods and were used to develop a scenario for testing radionuclide migration models within the IncoCopernicus project COMETES. The recommendations for the choice of the size of the computational compartments are suggested accounting for the characteristics of the water bodies.
\end{abstract}

\section{INTRODUCTION}

The data on the radioactive contamination of the Dnieper River and reservoirs have been used since the Chernobyl accident for the validation of the models of aquatic dispersion of radionuclides. Such studies were performed as in Ukraine [1-3] as within the international projects, e.g., IAEA VAMP Programme - River and Reservoir Modelling Working Group [4], ECP-3 Project of the Commission European Communities- Belarus, Russia, Ukraine Programme on the radiological consequences of the Chernobyl accident [5], and others. For these studies the special scenarios have been prepared including the systemised data on the water discharges, suspended sediment and concentrations of ${ }^{137} \mathrm{Cs}$ and ${ }^{90} \mathrm{Sr}$ in dilute and in suspended sediments of the Pripyat River and Dnieper River - the main tributaries to the Kiev Reservoir, as also the data about the hydrological and radiological parameters of the downstream reservoirs - Kanev, Kremenchug, Dneprodzerzhinsk, Zaporozhe and Kakhovka reservoirs.

At the end of $80-\mathrm{s}$ in early $90-\mathrm{s}$ the detailed studies of the water systems around the Chernobyl Nuclear Power Plant (NPP) have shown [1-4] , that very significant input to the radionuclide fluxes of the Pripyat River has been generated from the near river site at $10 \mathrm{~km}$ length upstream the Chernobyl NPP. Even particular inundation of the floodplain in this area has leaded to the significant increasing of radionuclide concentration in the Pripyat River. First large scale inundation of this floodplain site took place in January, 1991 due to the ice jam and it was followed up by the increasing of the ${ }^{90} \mathrm{Sr}$ concentration at the outlet cross-section of this area - Yanov Bridge till $10000-12000 \mathrm{~Bq} / \mathrm{m}^{3}$. The national maximum permissible level for ${ }^{90} \mathrm{Sr}$ concentration at this moment was $3700 \mathrm{~Bq} / \mathrm{m}^{3}$. The propagation of this "signal' from the vicinity of the Chernobyl NPP has been measured along $900 \mathrm{~km}$ pathway from the vicinity of Chernobyl NPP via Dnieper reservoirs till the estuary. In 1991-1992 the protective dike has been constructed to prevent the flooding of most contaminated areas on left-bank floodplain. However during each spring flood in 90- $\mathrm{s}$ it was measured increasing of the concentration of ${ }^{90} \mathrm{Sr}$ in Dnieper reservoirs due to the radionuclide wash-off from the contaminated and still non-protected areas. All this period the maximum discharges of the spring floods in the Pripyat River have had low or mean magnitude. The highest flood since the Chernobyl accident took place in the Pripyat River in the spring 1999 that was also followed up by the propagation of ${ }^{90} \mathrm{Sr}$ peak along the Dnieper reservoirs. These 
data as also the refined data sets for 1991 have been used within Inco-Copernicus project COMETES for the comparative analyses of the applicability of mathematical models of different dimension for simulation of such phenomenon.

\section{FLOOD 1999 - GENERATION of ${ }^{90}$ Sr FLUX FROM THE PRIPYAT RIVER}

\subsection{Water protection measures before the flood}

Since 1993 after the finalising of the construction of the above mentioned left-bank protective dike (Fig.1) the main sources of the radionuclide fluxes is the floodplain area situated at the right bank of the river, where at the Yanov Bay the density of the ${ }^{90} \mathrm{Sr}$ fallout exceeds $2 * 10^{13} \mathrm{~Bq} / \mathrm{km}^{2}$ (Fig. 2).

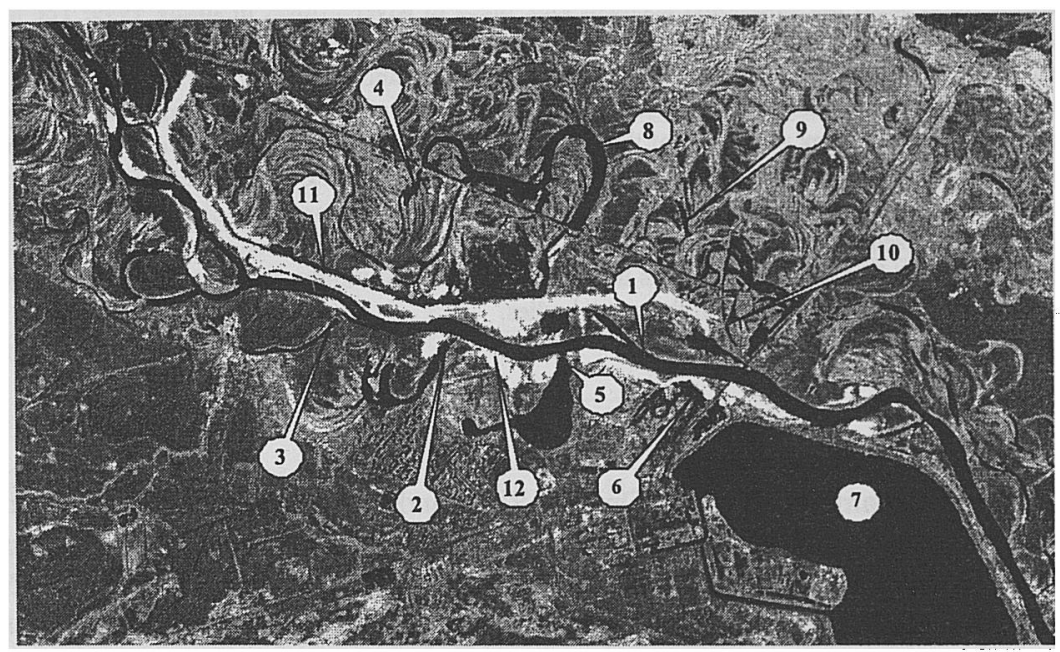

Figure 1: Water bodies upstream and at the Chernobyl NPP

1-Pripyat river channel; 2- Semihodi bay; 3-Shepelichi bay; 4- Glubokoe lake; 5- dike of Yanov bay; 6-the lakes and sandy dikes of the right bank at the Yanov Bridge; 7 - Cooling Pond of Chernobyl NPP; 8- old river channel; 9 . polder system; 10- drainage system; 11- left-bank flood protective dike, constructed in 1993.

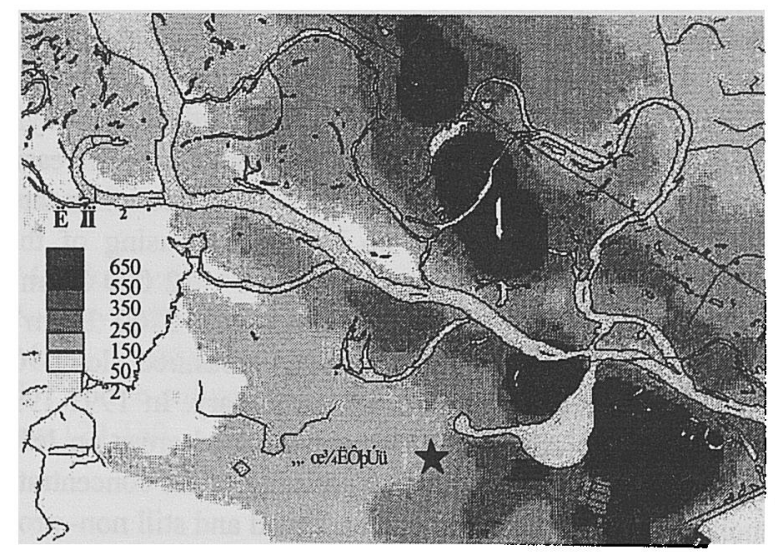

Figure 2: Density of ${ }^{90} \mathrm{Sr}$ fallout $\left(\mathrm{Ci} / \mathrm{km}^{2}=3.710^{10} \mathrm{~Bq} / \mathrm{km}^{2}\right)$ on the Pripyat River floodplain upstream the Chernobyl NPP 
The left -bank dike has width at the foundation up to $200 \mathrm{~m}$ and the elevation is $111 \mathrm{~m}$ above sea level, that excludes the overflow of water even in case of the flood with the frequency of occurrence one time per 100 years (the maximum water discharge up to $6000 \mathrm{~m}^{3} / \mathrm{s}$ ). At the end of the winter 1999 the right- bank dike was partially built (Fig.1). It was anticipated that the highest level of the dam would be not less than $109 \mathrm{~m}$. However, by the spring of 1999 its height in many parts was not more than 107 $107.5 \mathrm{~m}$.

\subsection{Flood 1999 events at the Chernobyl NPP}

The spring flood 1999 in the Pripyat River had maximum discharge $3000 \mathrm{~m}^{3} / \mathrm{s}$ that was the highest monitored discharge since the historically high flood of $1979\left(4500 \mathrm{~m}^{3} / \mathrm{s}\right)$. The floodplain inundation was started when water level has exceeded $106.5 \mathrm{~m}$ above the sea level and the water discharge has exceeded $1000 \mathrm{~m}^{3} / \mathrm{s}$ (Figure 3). The construction of the right-bank dike was not completed at the moment and part of the right-bank floodplain was flooded during two weeks, primarily due to the dike overflow. Two main sources of the Pripyat water contamination during the flood were:

An area on the right bank floodplain with elevation below $107.5 \mathrm{~m}$ which were flooded as a result of the dike overflow. The concentration of ${ }^{90} \mathrm{Sr}$ in the water discharged from this territory to the river at the end of the flooding has increased to $100000 \mathrm{~Bq} / \mathrm{m}^{3}$.

The flow from the Yanov Bay that has started at 4 April and continued to the end of May. Before the flood the bay was isolated from the river by the stone dike build in 1987. Due to the inundation of the surrounding territories the contaminated water of the bay and surrounding waste disposal places was discharged into the river.

As result of these wash-off processes the maximum measured concentration of ${ }^{90} \mathrm{Sr}$ at city of Chernobyl (at $10 \mathrm{~km}$ downstream the Yanov Bridge) has achieved maximum measured value 2000 $\mathrm{Bq} / \mathrm{m}^{3}$ and ten day averaged concentration has had maximum at $1500 \mathrm{~Bq} / \mathrm{m}^{3}$. The ten days averaged data of water discharge, suspended sediments and concentrations of ${ }^{90} \mathrm{Sr}$ and ${ }^{137} \mathrm{Cs}$ in the Pripyat River and upper Dnieper River at the inflow to the Kiev reservoir have been used to simulate radionuclide transport in this water body and other reservoirs of the Dnieper cascade.

\section{MODELS}

The box model WATOX [2], one-dimensional model RIVTOX [2,8] and three-dimensional model THREETOX [6,7] were used in the study of the radionuclide transport in Dnieper reservoirs during the 1999 flood. The model set simulates in different resolution the radionuclides concentration in solute, in the suspended sediments and in the bottom deposition. The exchanges between these variables are described as adsorption-desorption and sedimentation-resuspension processes. The adsorption/desorption and diffusion transfer in the systems "solution - suspended sediments" and "solution - bottom deposition" is treated via the distribution coefficient $\mathrm{K}_{d}$ values and the exchange rates between solution and particles are taken into account, for a more realistic simulation of the kinetics of the processes. It is assumed that the adsorption and desorption rates are not equal. For the simulation of the Dnieper reservoirs by WATOX, the Kiev Reservoir and Kremenchug Reservoir were considered as two-box systems (upper shallow part, and downstream deeper part) and other reservoirs were considered as one box each.

\section{RADIONUCLIDE TRANSPORT IN DNIEPER RESERVOIRS}

The measurements of the radionuclide concentrations in Kiev reservoir at Hydro Power Plant ( city of Vyshgorod) were presented by the several institutions. It was provided statistical processing of all collected data for spring 1999 (Fig. 3) that shows a clear peak distribution of the ${ }^{90} \mathrm{Sr}$ concentrations in the Kiev reservoir with maximum value at $1000 \mathrm{~Bq} / \mathrm{m}^{3}$. 


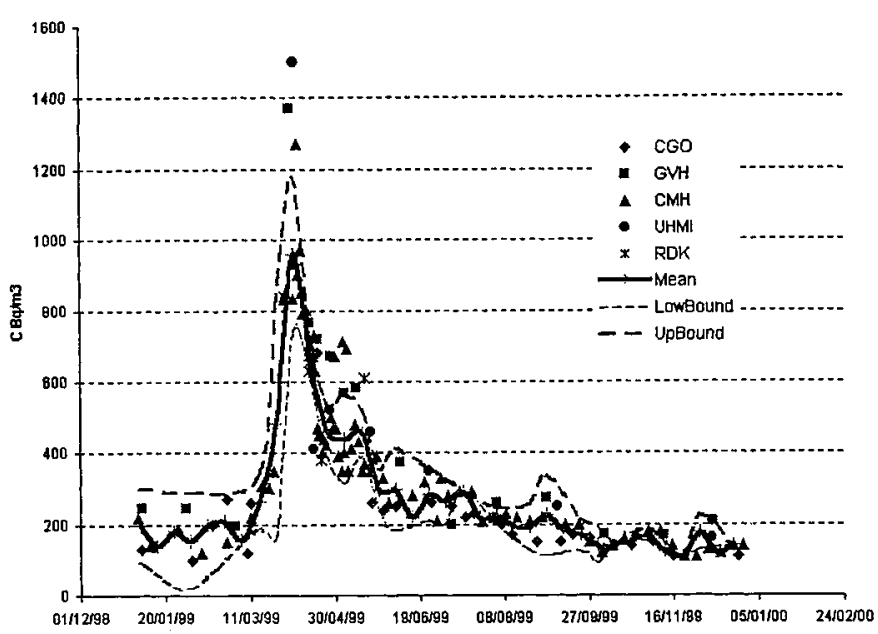

Figure 3: Concentration of ${ }^{90} \mathrm{Sr}$ in Kiev Reservoir at dam of Hydro Power Plant in 1999 measured by different institutions and results statistical processing of these data - mean value, upper and lower bounds of the confidential band.

The results of the simulation of the concentration of ${ }^{90} \mathrm{Sr}$ in the Kiev reservoir obtained by all three used models (Fig. 4) are in the confidential interval of the measured data. The box model due to the assumed full mixing in the compartments has produced some lower value of the maximum concentration than distributed 1-D and 3-D models.

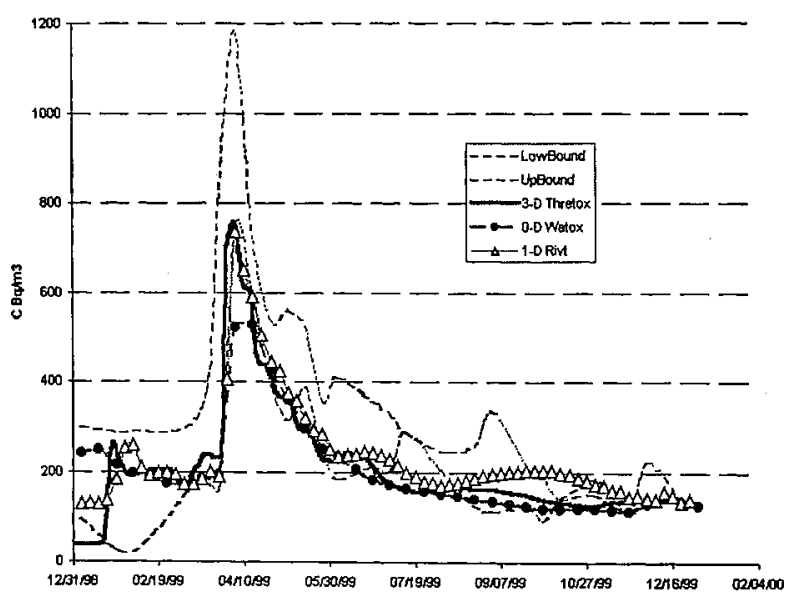

Figure 4: Concentration of ${ }^{90} \mathrm{Sr}$ in Kiev Reservoir at dam of Hydro Power Plant in 1999 simulated by 0-dimensional (box) model, one-dimensional model and three-dimensional model in comparison with the bounds of the confidential band of the measured data

The 3-D model does not predict radionuclide concentrations at the reservoir outlet better than the models of lower dimension. Nevertheless, the complex 3-D model is necessary for assessing the spatial distribution of radionuclide concentration in large water body (Fig. 5). A typical example is the predictions of radionuclide contamination at different locations of water usage. 

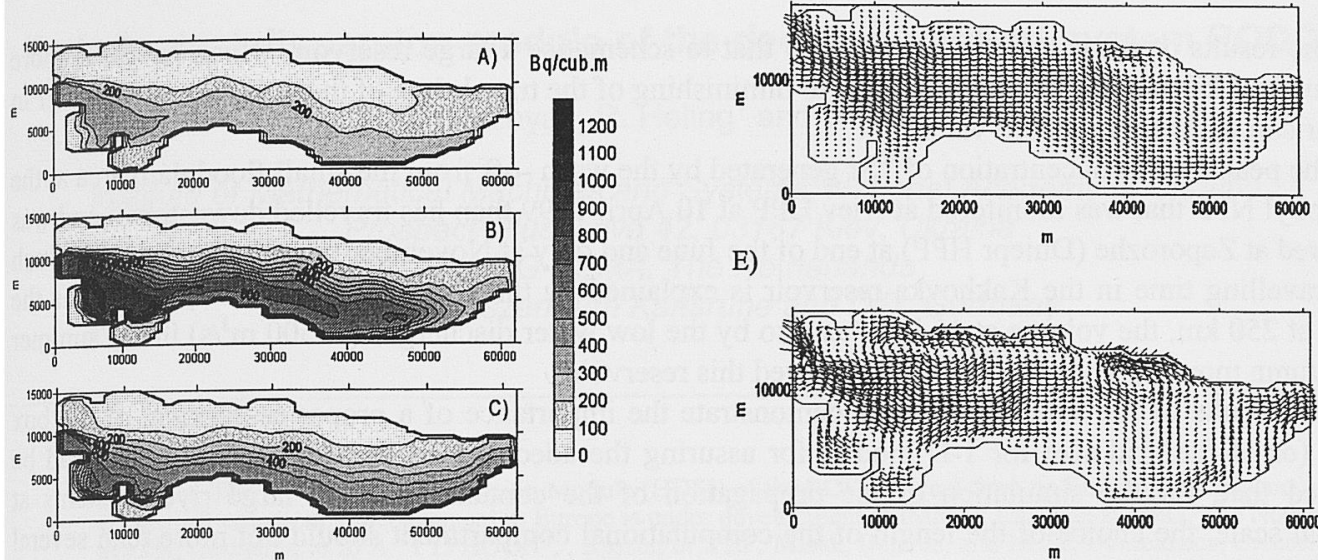

E)

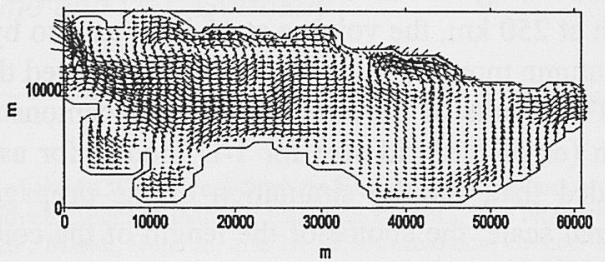

F)

Figure 5: Simulated by 3-D model concentration of ${ }^{90} \mathrm{Sr}$ at the surface of Kiev Reservoir in A) $\left.5 \mathrm{March}, \mathrm{B}\right) 25 \mathrm{March}$ and C) 15 April 1999 and simulated currents at the bottom E) and at the surface for the conditions of N-W wind, wind velocity $|\mathrm{W}|=5.3 \mathrm{~m} / \mathrm{s}$, maximum currents velocity $|\mathrm{U}| \max =16 \mathrm{~cm} / \mathrm{s}, \mathrm{Q}=1100 \mathrm{~m}^{3} / \mathrm{s}$.

The 1-D model and the box models were used to simulate the whole reservoir cascade (Fig. 6).
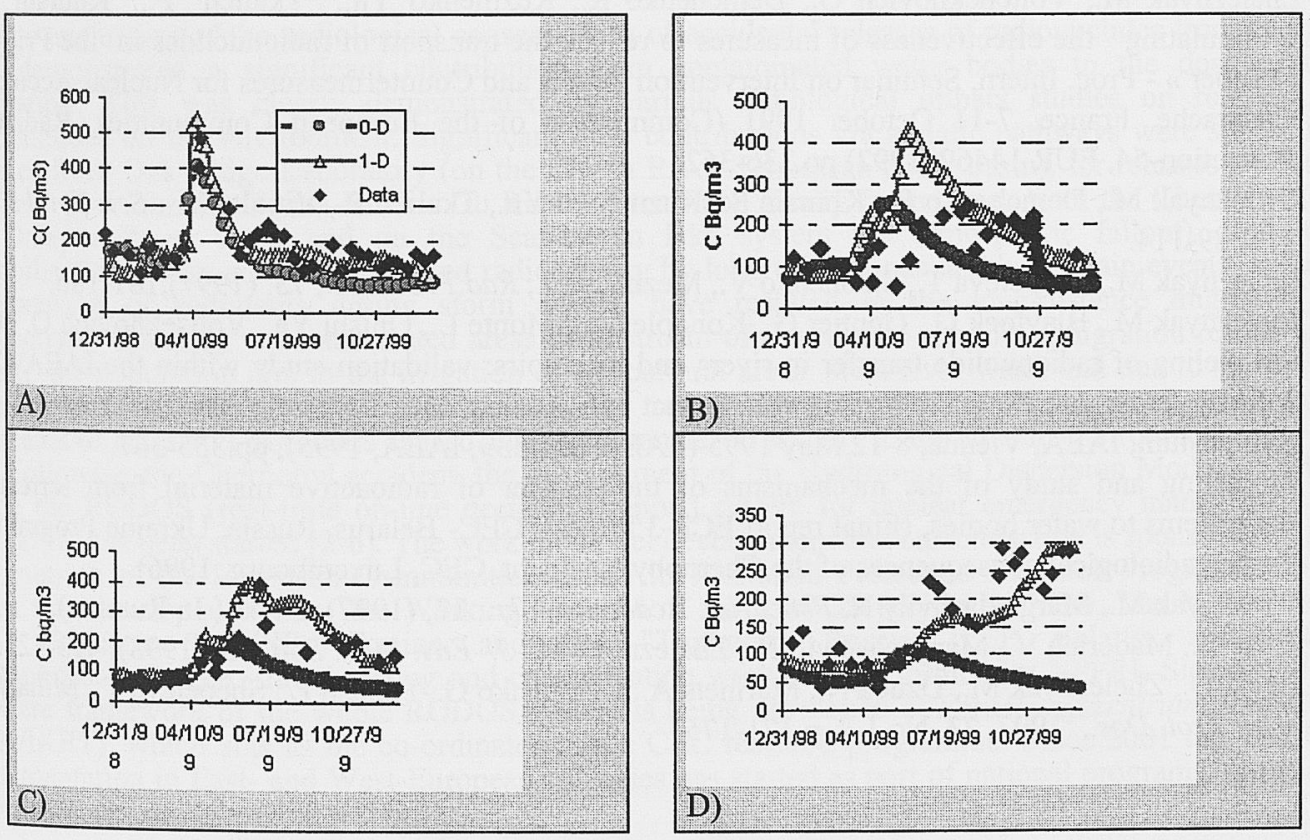

Figure 6: The ten-days averaged concentrations of ${ }^{90} \mathrm{Sr}$ at the HPP of A) Kiev Reservoir, B) Kremenchug Reservoir, C) Zaporozhe Resevoirs, D) Kakhovka Reservoir in comparison with the simulation results of the 0-dimensional (box) and 1dimensional models. 
The results of the calculation clear show that to schematise a large reservoir, which length is more than hundred kilometres, by one box leads to diminishing of the travel time of the pollutant in reservoir in comparison with the measured values.

The peak of the concentration of ${ }^{90} \mathrm{Sr}$ generated by the wash -off from the small floodplain area at the Chernobyl NPP that was monitored at Kiev HPP at 10 April 1999 than has travelled downstream and was measured at Zaporozhe (Dniepr HPP) at end of the June and only at November near Kakhovka HPP. Such long travelling time in the Kakhovka reservoir is explained by the size of this reservoir, which has the length at $250 \mathrm{~km}$, the volume at $16 \mathrm{~km}^{3}$, as also by the low water discharges (at $500 \mathrm{~m}^{3} / \mathrm{s}$ ) in the summer and autumn months, when the peak has achieved this reservoir.

The results of the simulations clear demonstrate the importance of a proper assessment of the box length (or of the grid size for 1-D model) for assuring the adequacy of the model results. It could be provided that, for the simulation of the propagation of the contamination in large river systems at seasonal scale, the choice of the length of the computational compartment should not more than several tenths of kilometres.

\section{Acknowledgements}

The study was supported by Inco-Copernicus project COMETES "Implementing computerised methodologies to evaluate the effectiveness of countermeasures for restoring radionuclide contaminated freshwater ecosystems".

\section{References}

[1] Zheleznyak M., Voitchekhovich O., Demchenko R., Kuzmenko Yu., Tkalich P., Khursin S., "Simulating the effectiveness of measures to reduce the transport of radionuclides in the PripyatDnieper » - Proc. Intern. Seminar on Intervention Levels and Countermeasures for Nuclear Accidents Cadarache, France, 7-11 October 1991 (Commission of the European Communities, Radiation Protection-54, EUR 14469, 1992) pp.336-362.

[2] Zheleznyak M., Demchenko R., Khursin S., Kuzmenko Yu., Tkalich P., Vitjuk N.. - Sci. Total Env., 112, 89-114.

[3] Zheleznyak M., Shepeleva T., Sizonenko V., Mezhueva I., Rad.Prot.Dos., 73, (1997),181-186.

[4] Zheleznyak M., Blaylock G., Gontier G., Konoplev A., Monte L., Onishi Ya., Voitsekhovich O. et al. "Modeling of radionuclide transfer in rivers and reservoirs: validation study within the IAEAICEC VAMP Programme" Environmental Impact of Radioactive Releases, Proc.of International Symposium, IAEA, Vienna, 8-12 May 1995 (IAEA-SM-339, IAEA, 1995), pp.355-367.

[5] Modelling and study of the mechanisms of the transfer of radioactive material from terrestrial ecosystems to water bodies, (Final report ECP-3 Project, CEC- Belarus, Russia, Ukraine Programme on the radiological consequences of the Chernobyl accident. CEC, Luxembourg, 1996).

[6] Zheleznyak M., Margvelashvily N. Proc. Nat. Acad. Sci. Ukr., 12, (1997), 36-43 (In Russian).

[7] Koziy L., Maderich V., Margvelashvili N., Zheleznyak M. J. Env. Mod. Soft. 13, (1998), 413-421.

[8] Slavik O., Zheleznyak M., Dzuba N., Marinets A., Lyashenko G., Papush L., Shepeleva T., Mihaly B. Rad. Prot. Dos., 1997, 73, No.1-4, p.171-175. 